\title{
Total Synthesis of Amphidinolide $\mathbf{E}$
}

\author{
Porino Va and William R. Roush* \\ Departments of Chemistry and Biochemistry \\ Scripps Florida, Jupiter, FL 33458 \\ e-mail: roush@scripps.edu
}

\section{Supporting Information:}

Selected ${ }^{1} \mathrm{H}$ NMR and ${ }^{13} \mathrm{C}$ NMR Spectra for Key Compounds 


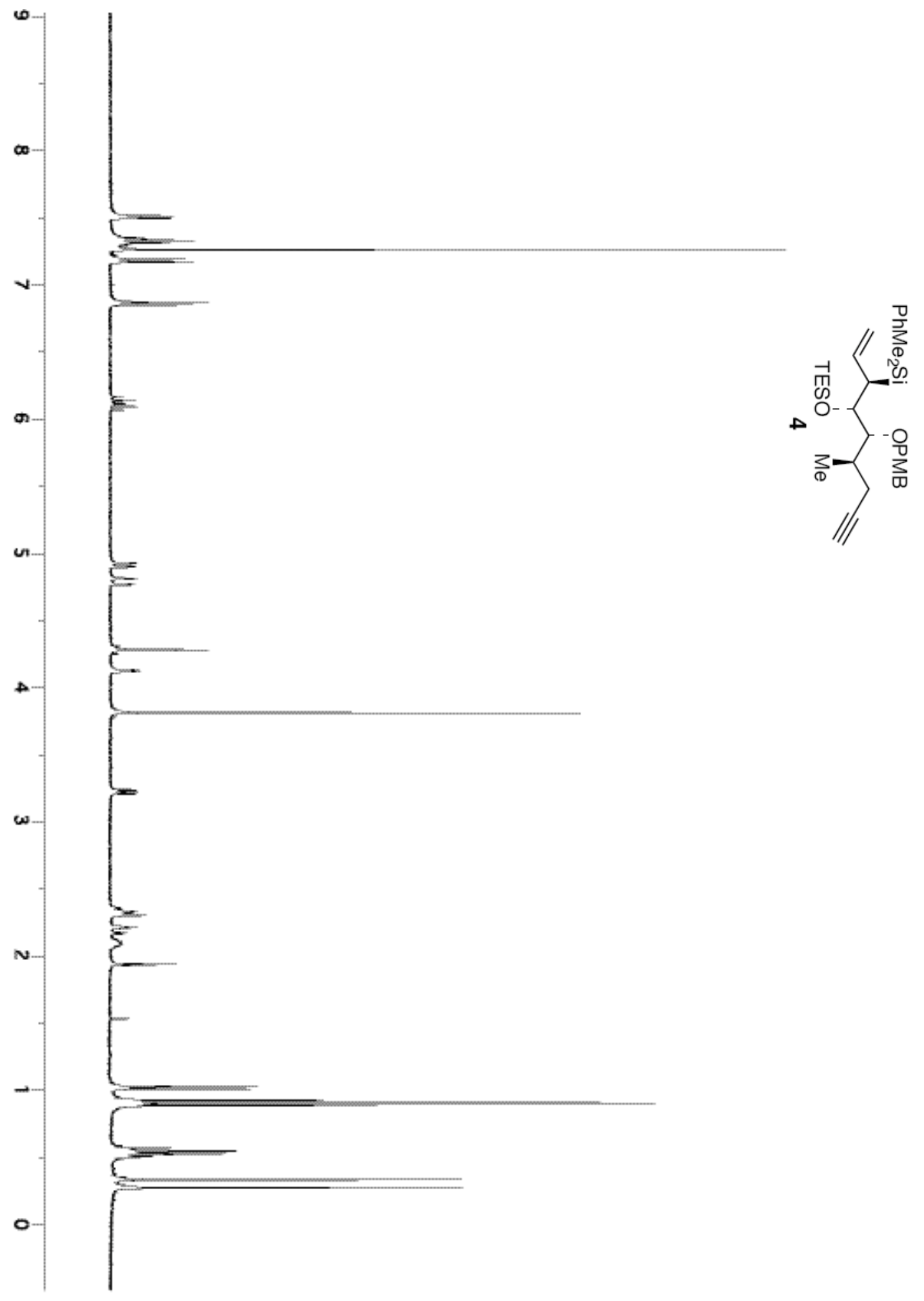

SI-2 


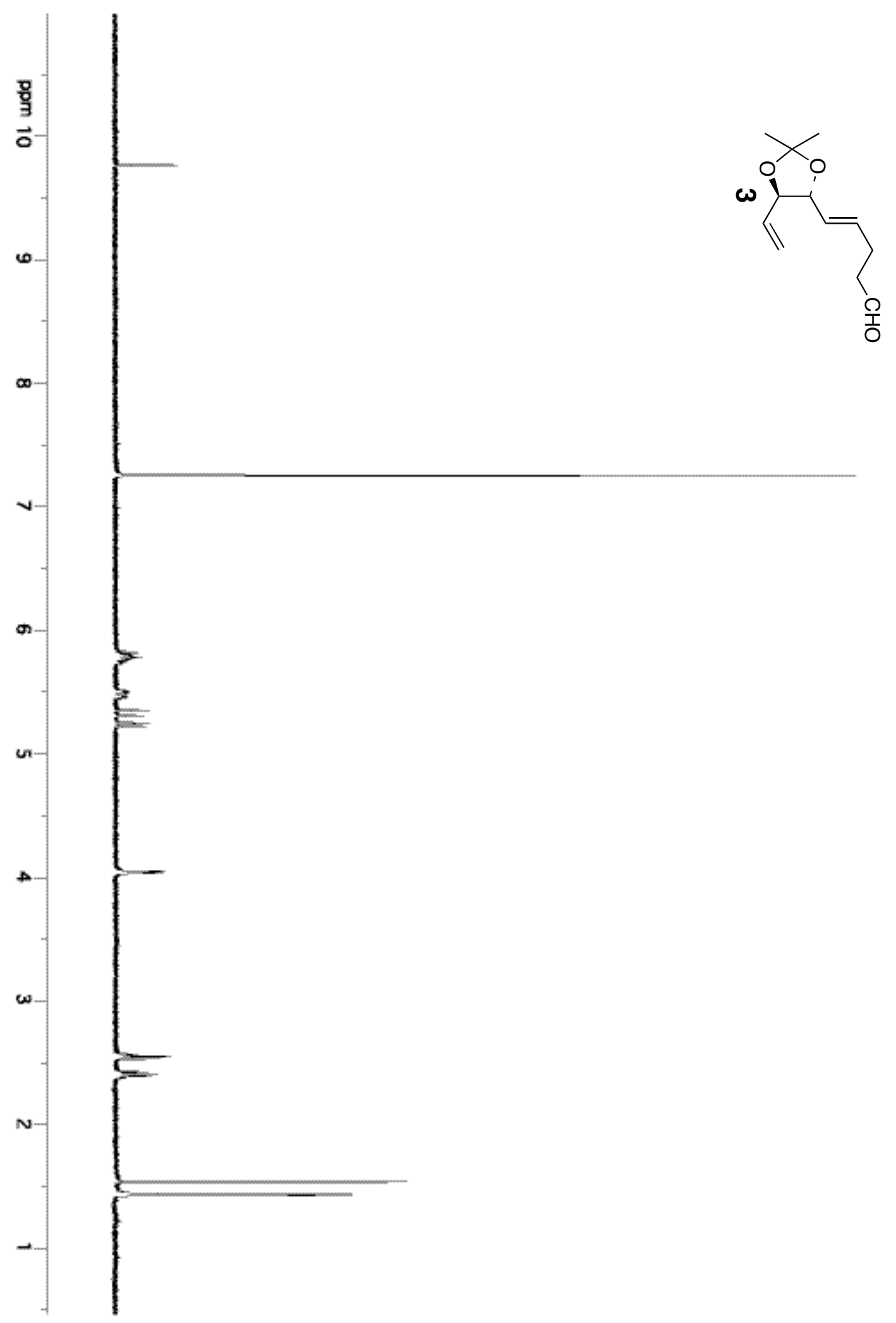

SI-3 


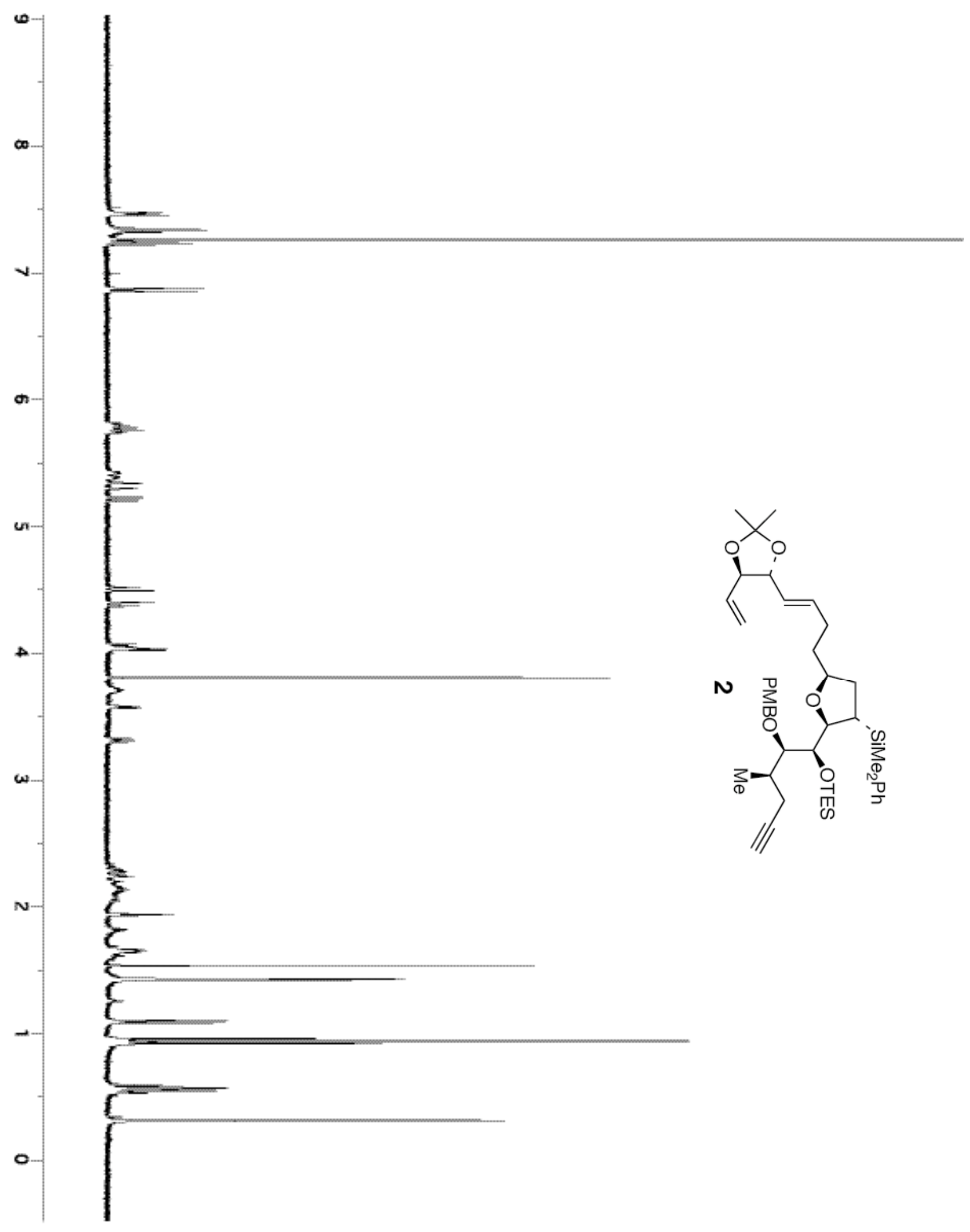

SI-4 


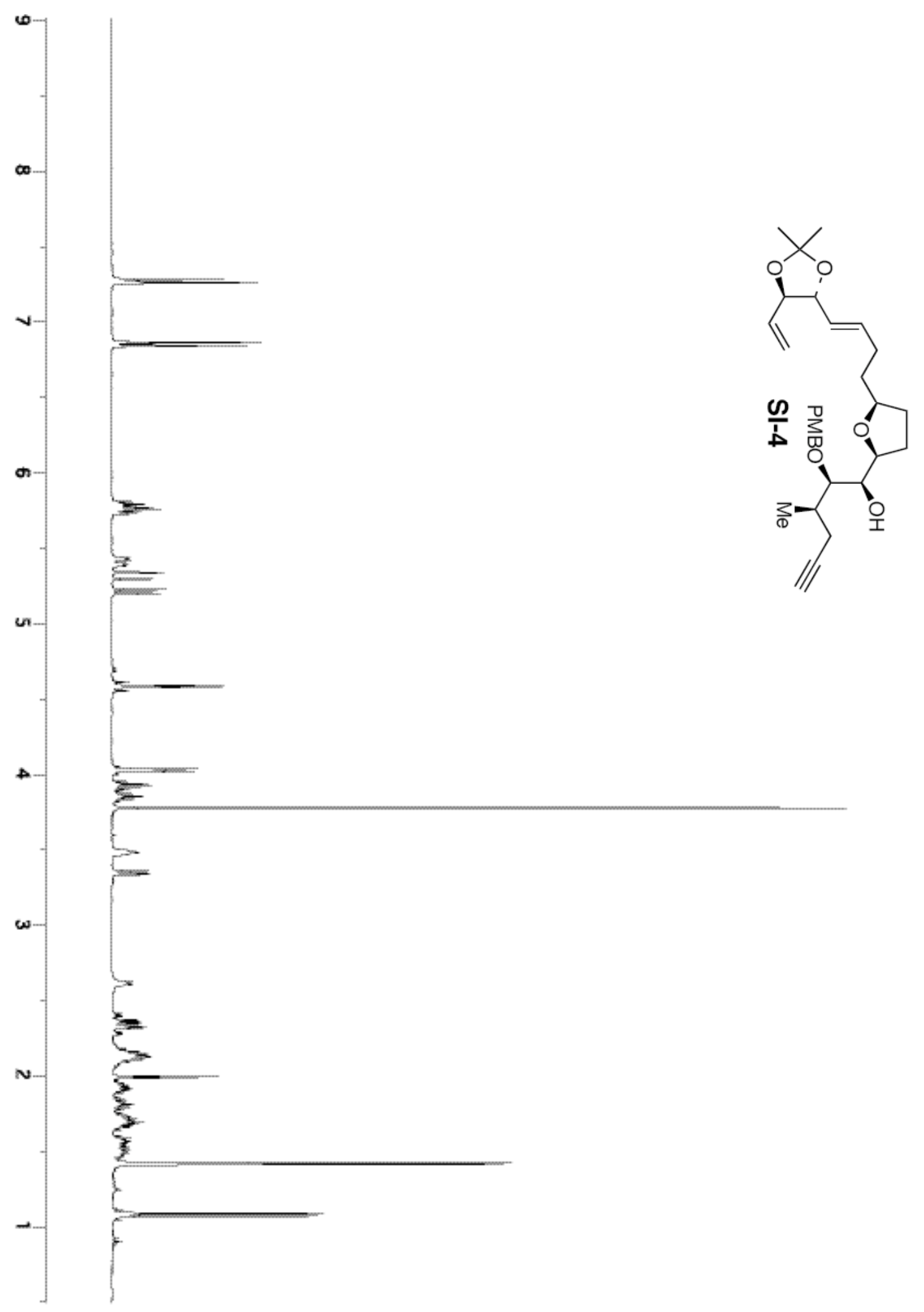

SI-5 


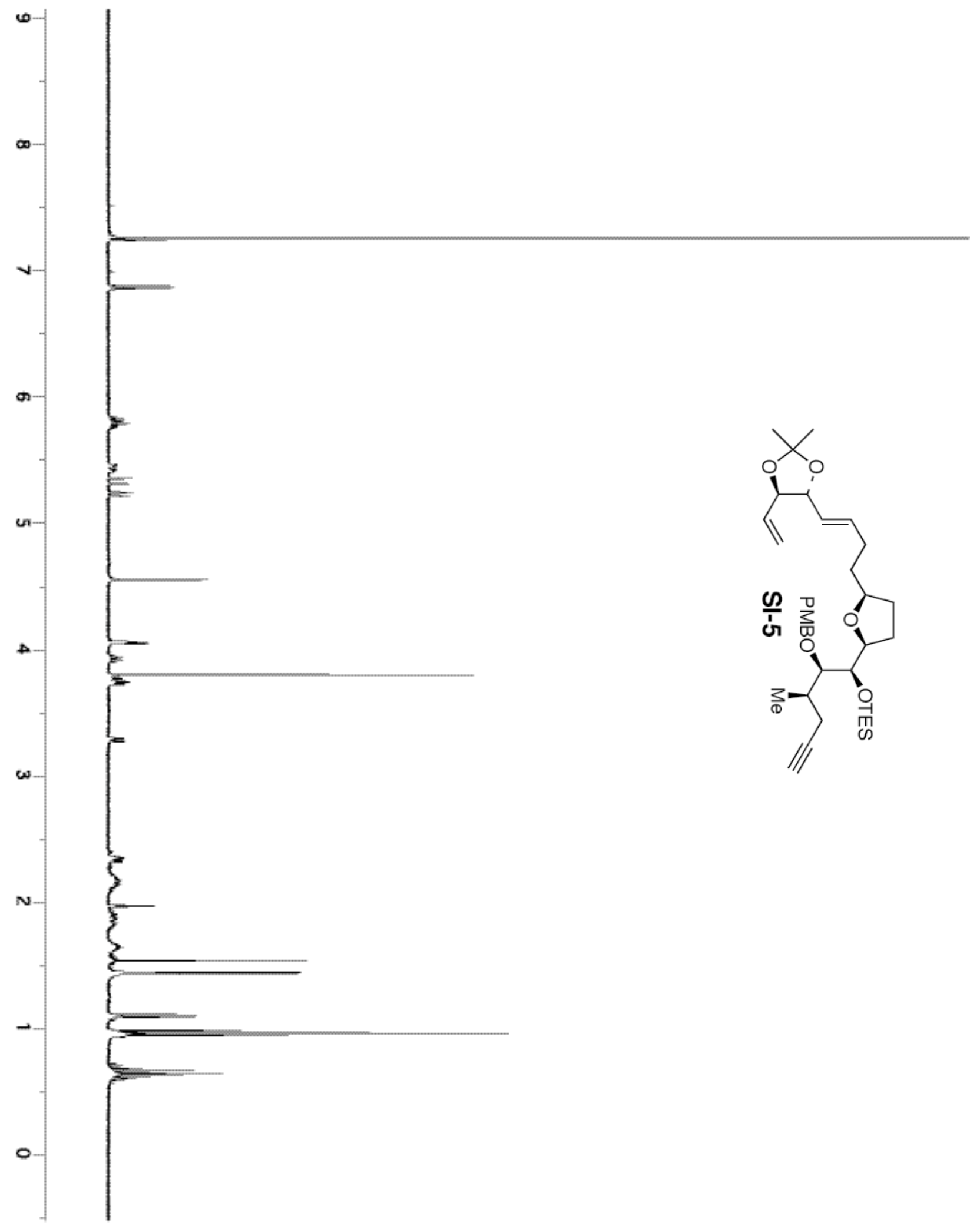




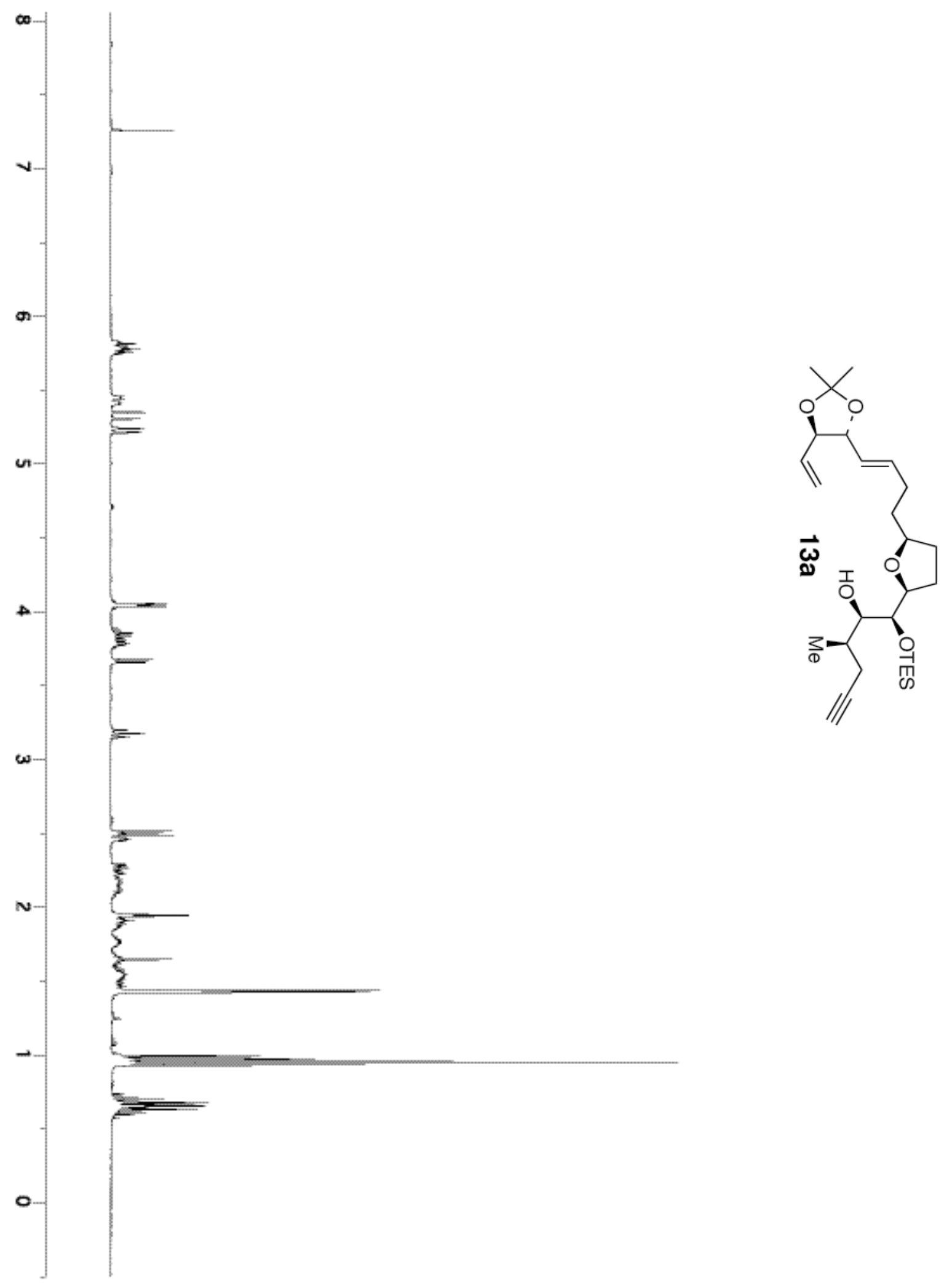

SI-7 


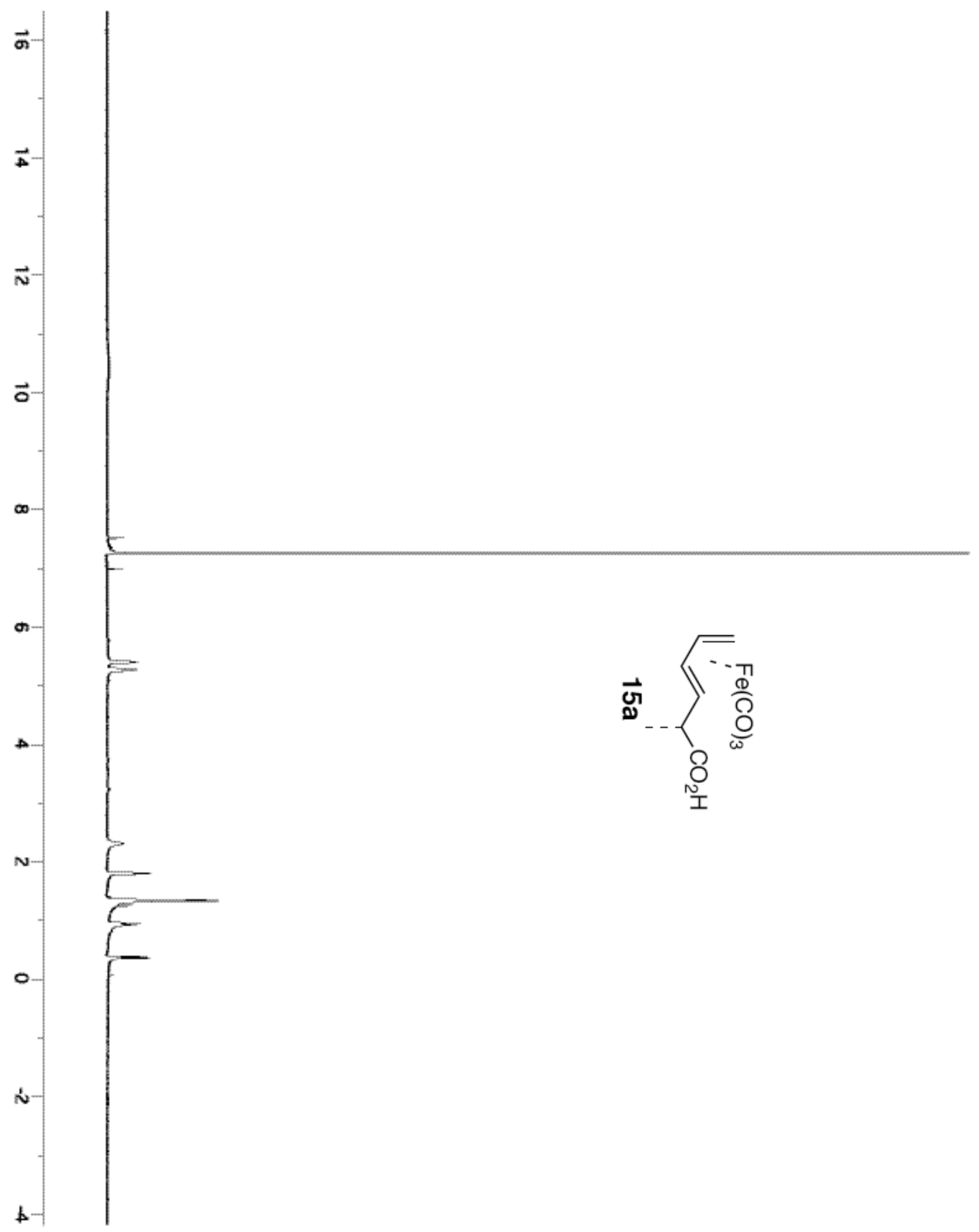




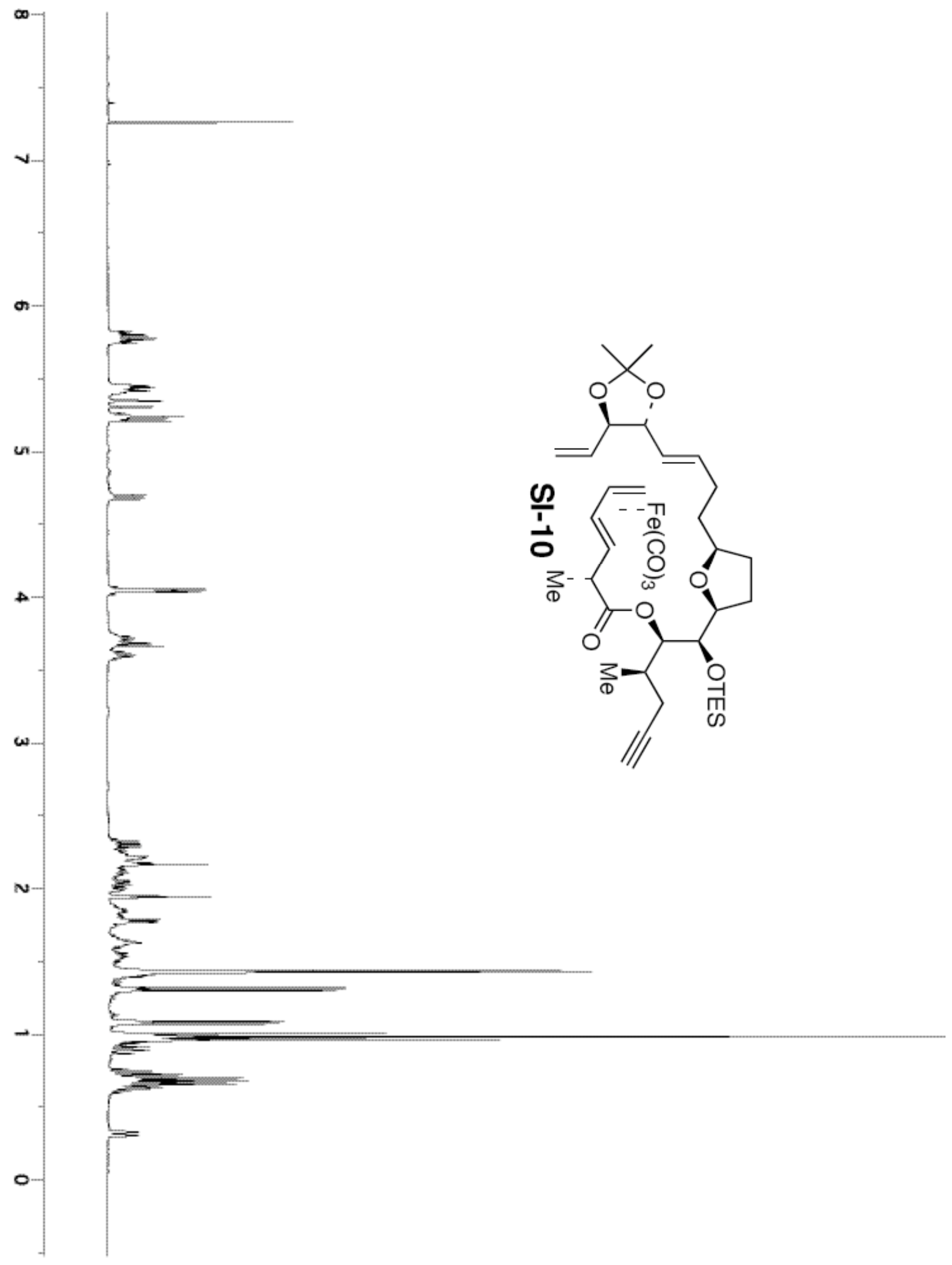




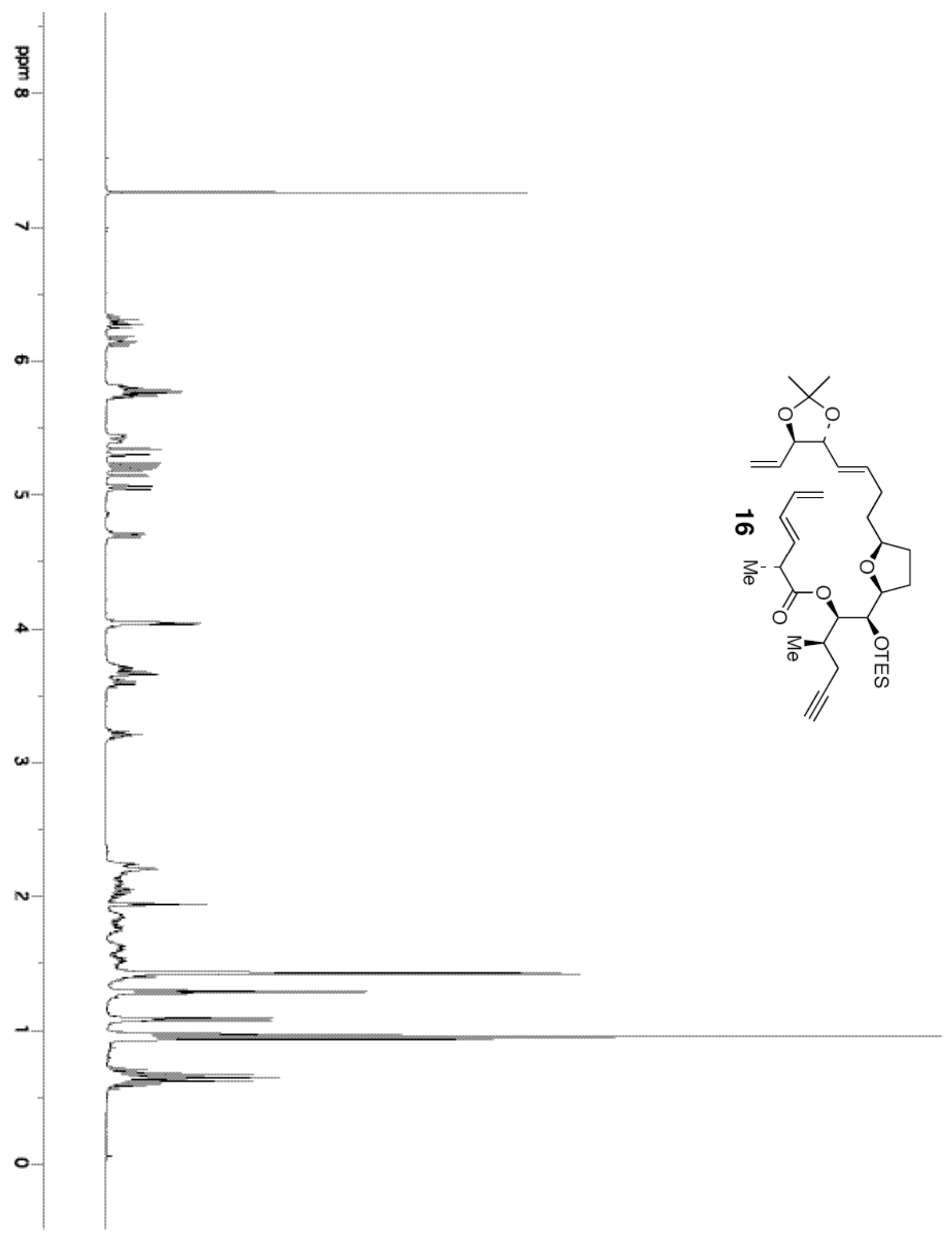

SI-10 


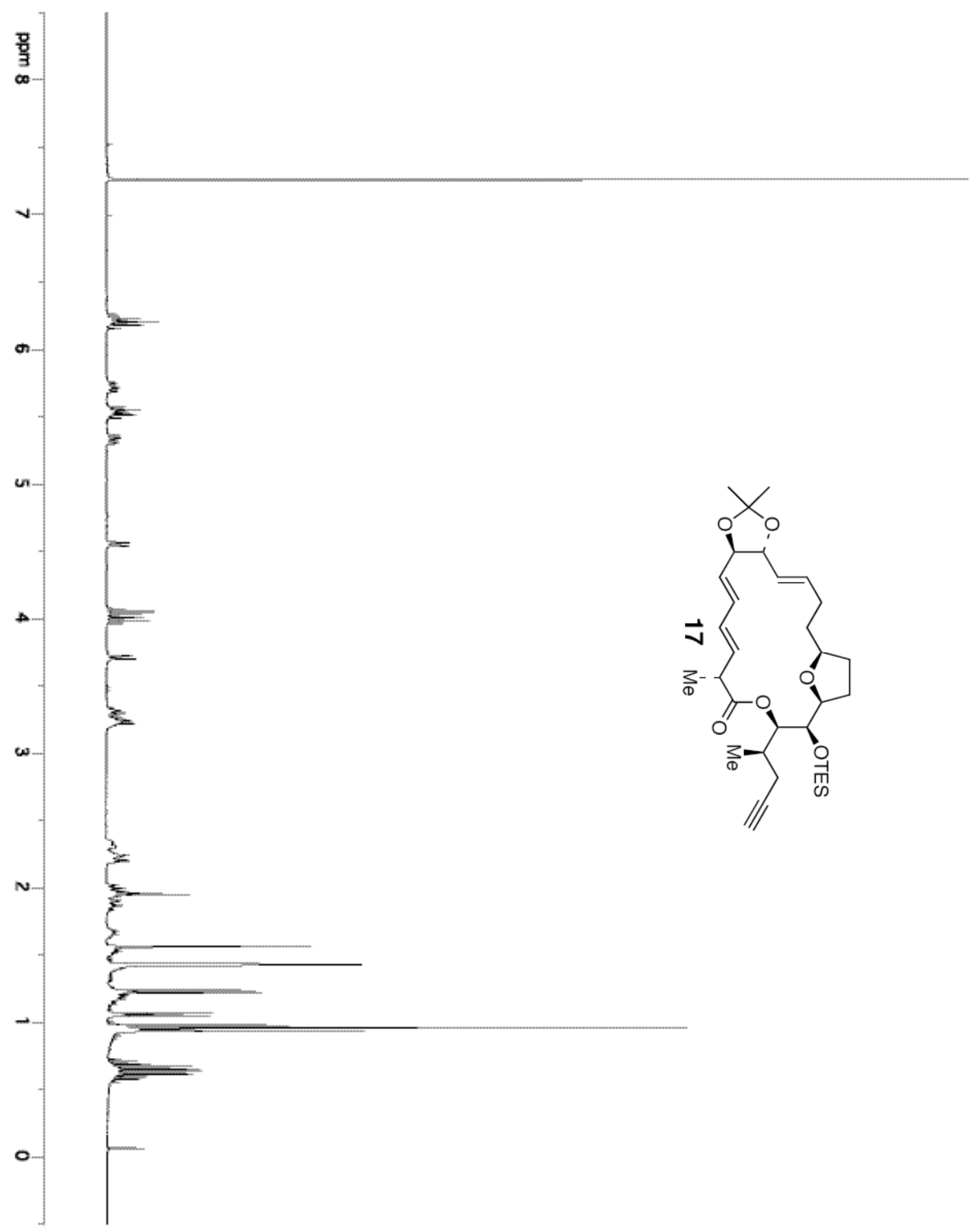

SI-11 


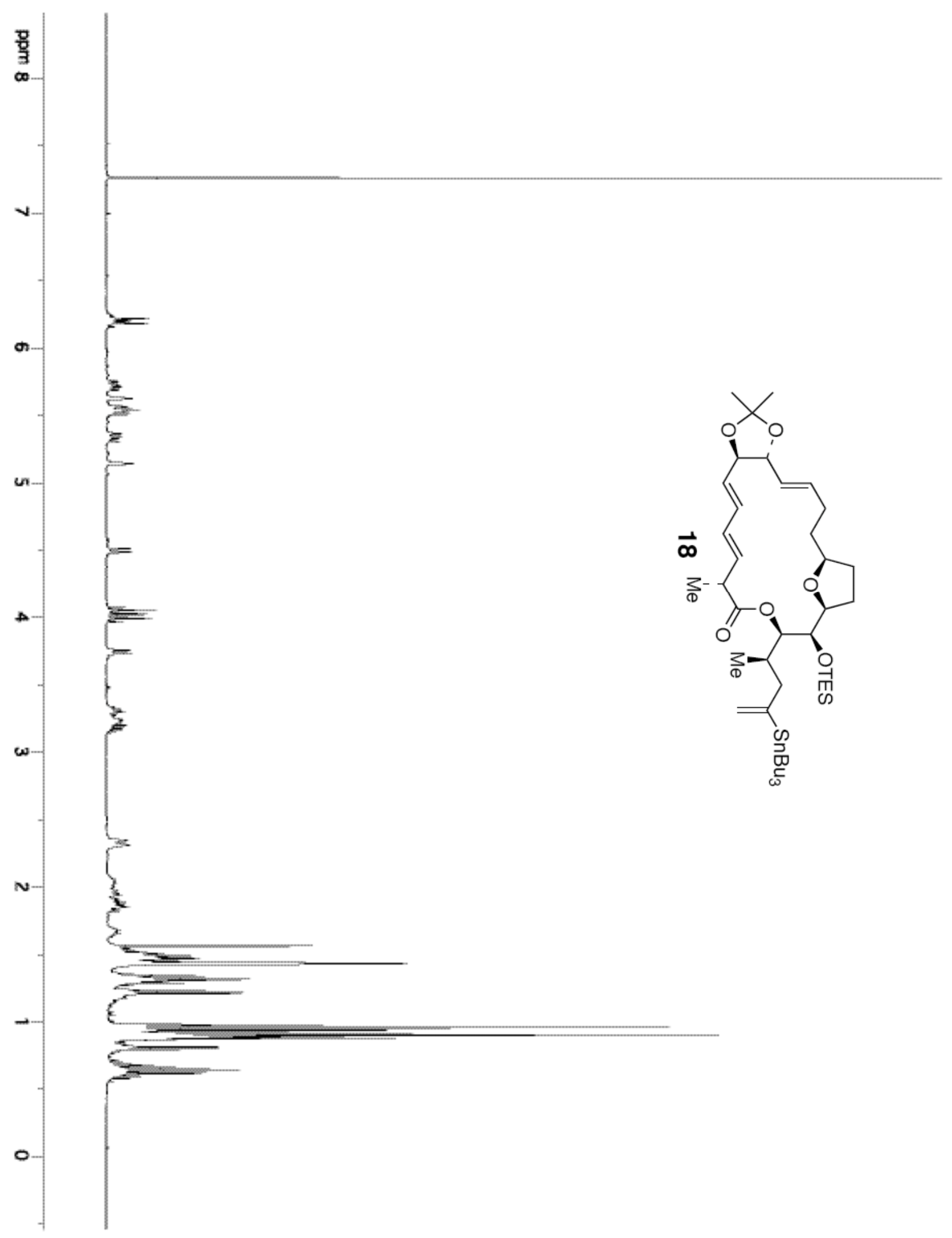

SI-12 


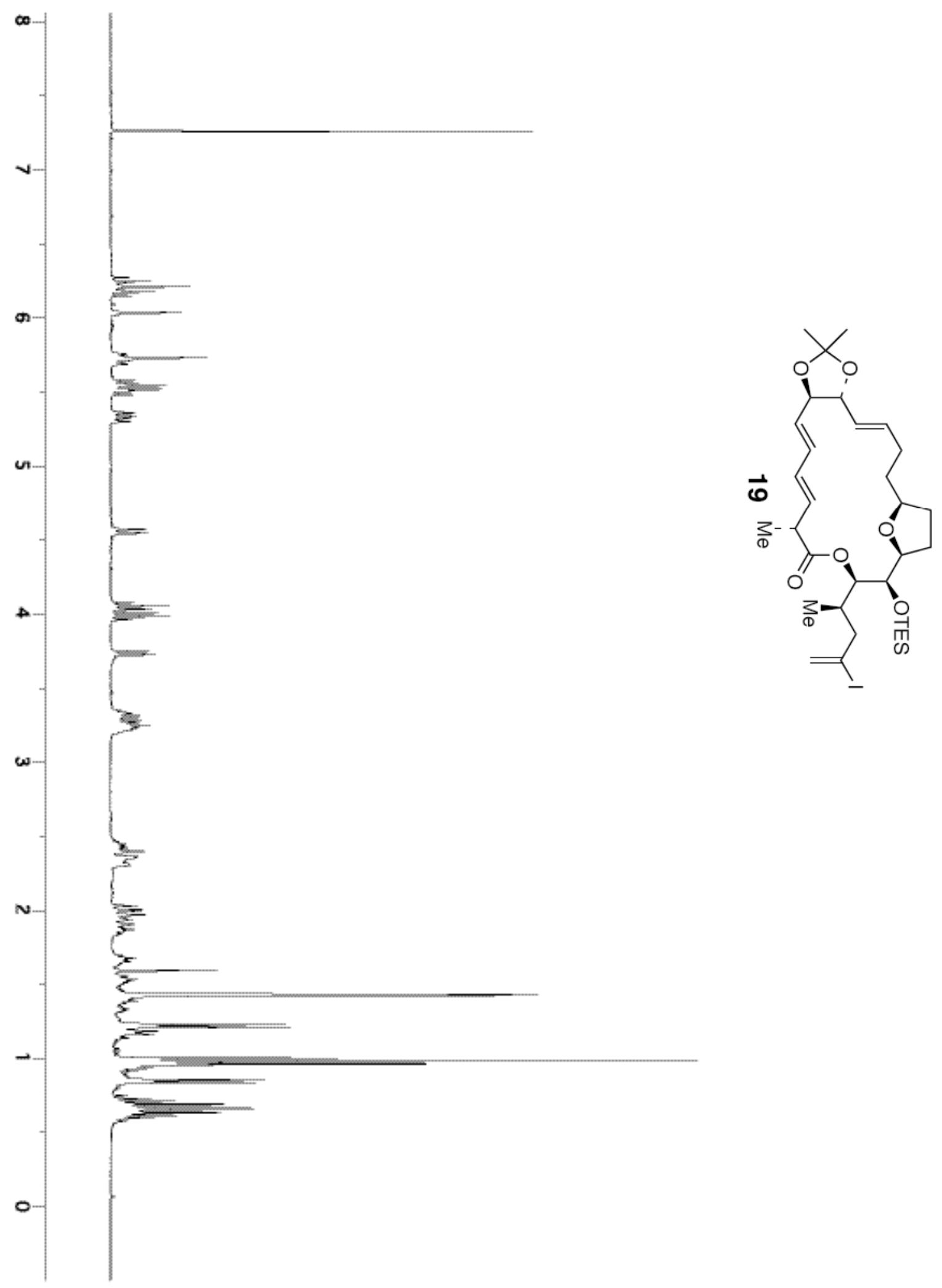

SI-13 


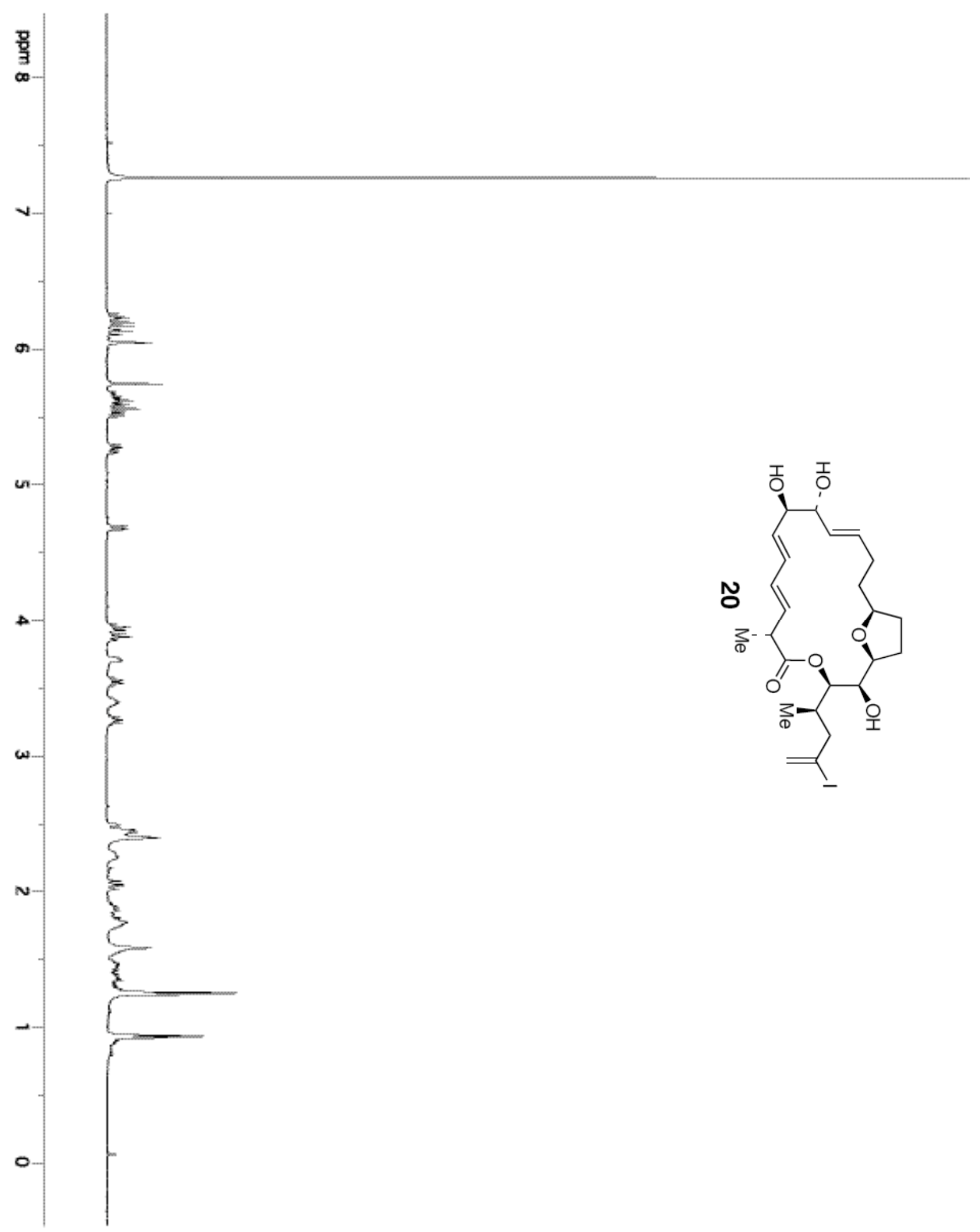

SI-14 


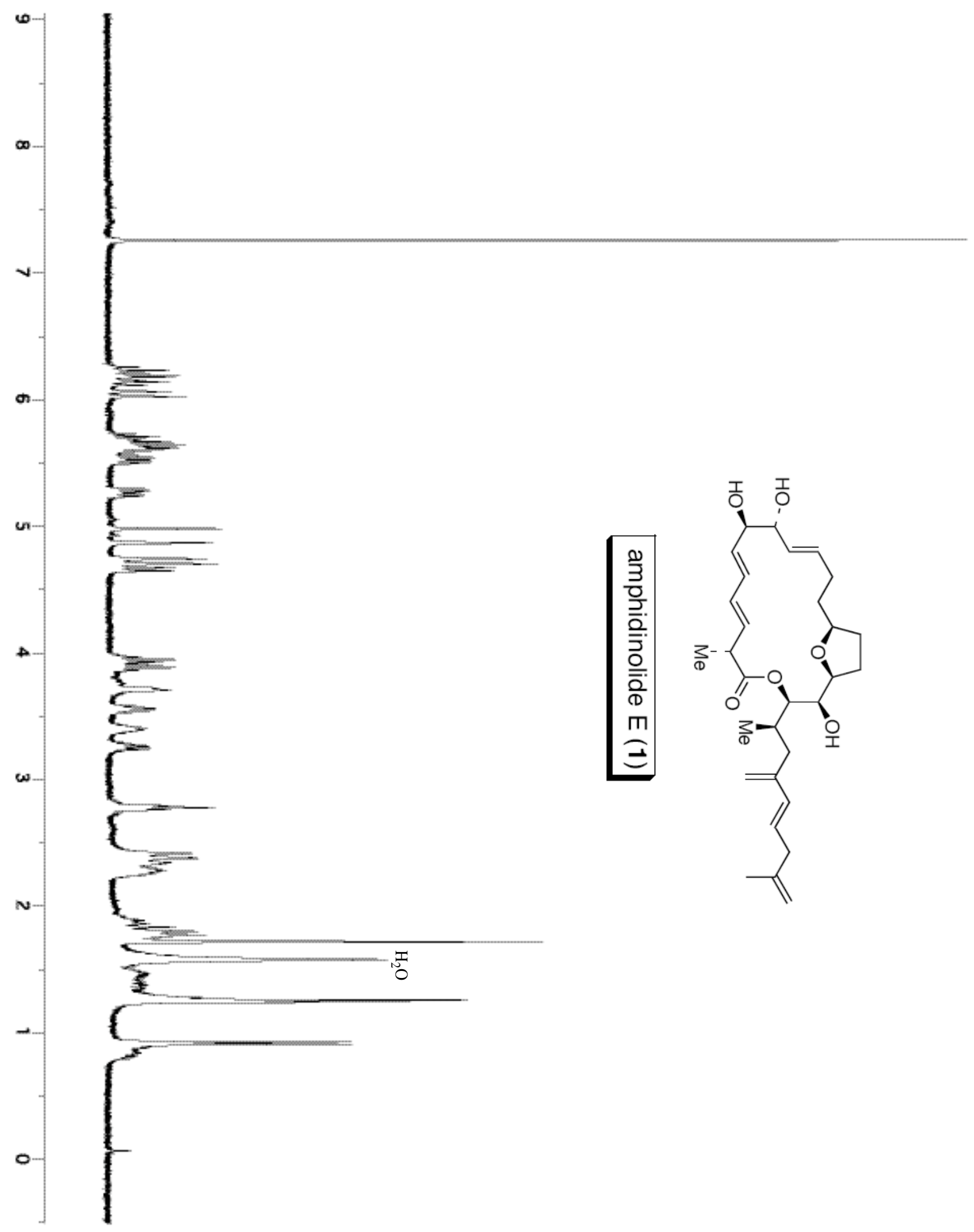

SI-15 


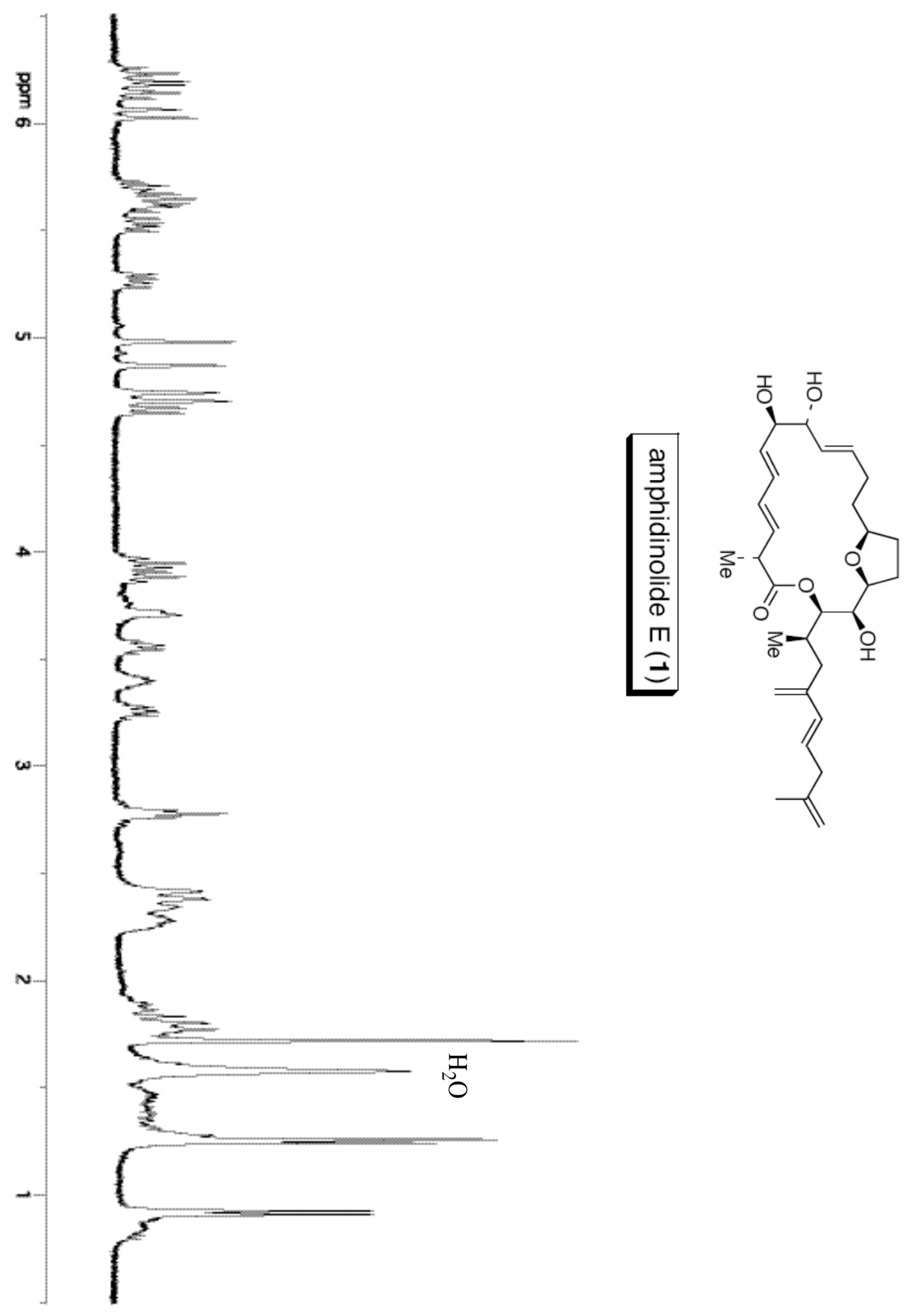

SI-16 


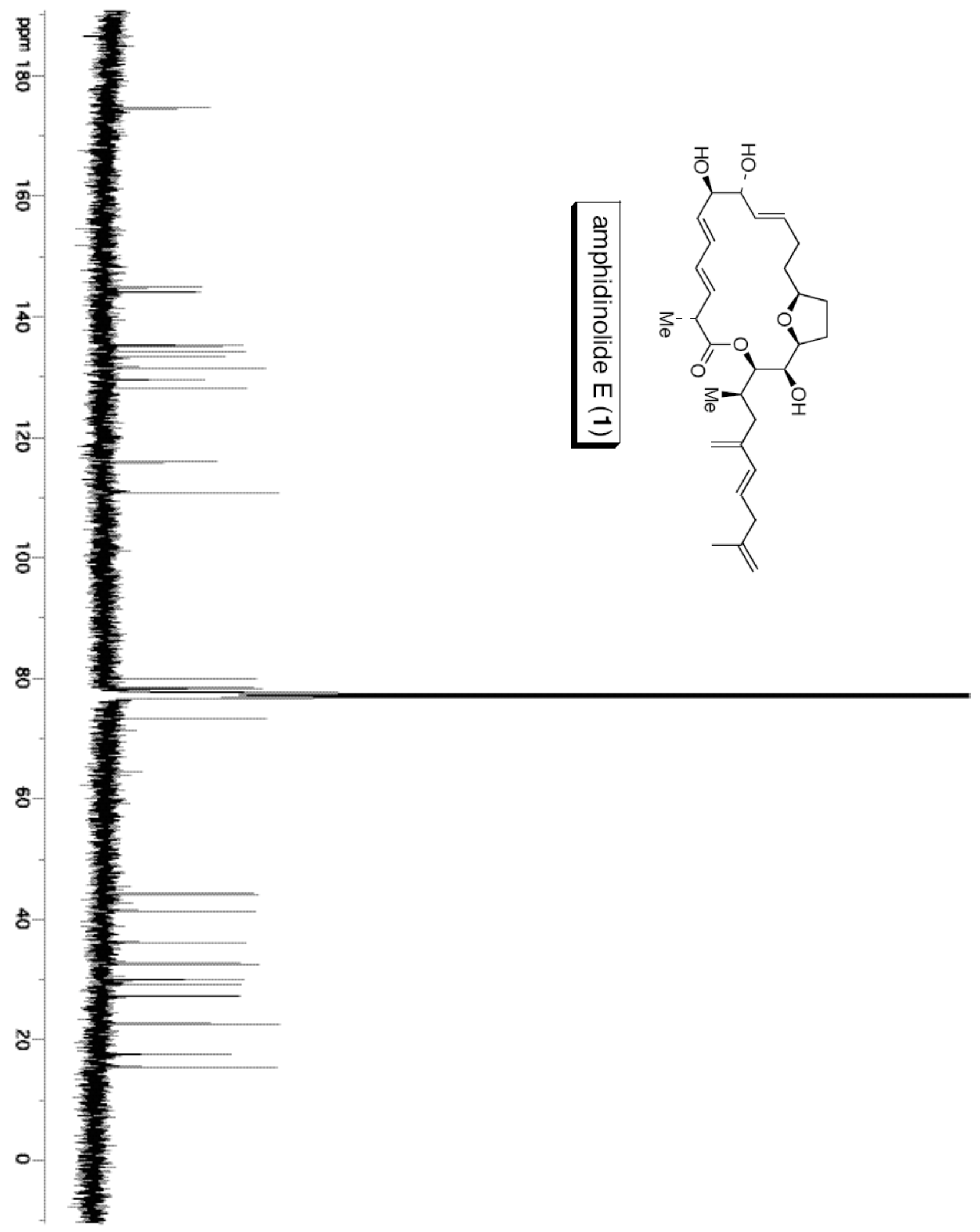

